\title{
Adaptation of the Nervous System to Training
}

\author{
Mir Sharif Hasan* \\ Student Counselor (Sports) North Bengal International University Rajshahi, Bangladesh.
}

*Corresponding Author: Mir Sharif Hasan, Student Counselor (Sports) North Bengal International University Rajshahi, Bangladesh.

\begin{abstract}
The nervous system of man is well adapted to the needs of a high developed organism. As is known in a complex organism like man, the nervous system plays a leading role in the regulation of all physiological processes and in effecting the connections between the organism and the external environment. Consciousness, abstract thought, memory, the interpretation of emotions, voluntary and involuntary movements, secretion of the glands, Cardiovascular and pulmonary activities etc.
\end{abstract}

The functional alterations in the nervous activities appear during the process of systematic sports activities. Systematic sports training has a positive effect on excitation and inhibition processes of the cerebral cortex.

In athletes one can state a higher nervous strength and flexibility but outbalanced nervous activities. The reason for this statement is related to an increase in excitability and lability of the nervous cells.

Keywords: Nervous system plays a leading role, regulating of all physiological process, connecting between the organism and external environment systematic sports training has a positive effect increase in excitability and lability of the nervous cells.

\section{Analysis}

During the training there is a continuous shortening of the latent period of conditioned reflexes, the ability of better differentiating negative stimulus is improved and accessory actions during movements are reduced. In addition to this, systematic training reduces excessive excitation of the nervous system. Well trained athletes are much more capable of increasing their working level to the highest degree within a relatively short time or to switch over to another type of muscular activity than non athletes. Movement of athletes are more exact, precise and secure.

The nervous activity of the athletes depends on the specific sports activity performed. In disciplines with accelerated reactions, excitability of nervous action and lability of the nervous tissue is increased. Vice versa a reduction of nervous mobility can be stated in athletes performing endurance disciplines.

The trophic function of the nervous system and especially of the cerebral cortex is of high importance for the functional and morphological condition of organs and systems of organs. The trophic function of the nervous system is its positive action on metabolism and the metabolic supply of the tissues, organs and systems of organs. It is caused by the vegetative innervation of all parts of the body and under the influence of systematic training, profound alterations of the functional state of the vegetative nervous system will occur. In athletes one can observe an increase in parasympathetic tone at rest but during load the activity of the sympathetic division of the nervous system may be much more increased than in non athletes. Consequently the vegetative nervous activity is widened in direction of a stronger influence of the sympathetic division at work as well. During this development excitability of both the sympathetic division and the parasympathetic division is slightly decreased that is the vegetative nervous activity becomes more stable. As a result a higher functional capacity of organs and systems of organs is established accompanied by a higher economy of functions. Well known is the tropic influence on cardiac activities in athletes, where bradycardia dominates at rest.

\section{DEVELOPMENT OF ABILITIES OF MOVEMENTS}

The ability of movement is a specific manner of movement being developed during the training period and being characterized by automatic components. All the abilities of movements based on voluntary 
actions are developed on the basis of complicated conditioned reflexes. The process of developing the abilities of movements is subdivided into three phases:

\section{1. ${ }^{\text {st }}$ Phase Called Generalization}

During this stage of development additional and unnecessary excitations and widespread irradiations are characteristic in brain activities. As a result of these unnecessary irradiations, additional muscular contractions appear and the movements seem to be performed unsecurely and under high tension. During this period of training additional energy output is necessary and that is why the athlete easily fatigues.

\section{2. ${ }^{\text {nd }}$ Phase, Called Concentration}

This phase is characterized by inhibitions of the nervous centres. Irradiation of nervous impulses in the cerebral cortex is reduced. Related to this a systematic differentiation of abilities of movements is developed. The movements become more and more exact, additional muscular tension disappears, unnecessary movements become more and more restrained. The development of a dynamic motor stereotype starts during this second period. But it is still insufficiently stabilized. Strong stimulus, effecting the organism during this period, may extinguish existing inhibitions. As a result mistakes in performance of certain movements appear that is cramped and inexact movements.

\subsection{3 ${ }^{\text {rd }}$ Phase, Called Stabilization}

This period is the application of the dynamic motor stereotype and it is more stable than the previous phase. Related to this, excitation and inhibition processes run in an explicit succession. That is why the newly developed chain of conditioned reflexes has become a cerebral-cortex-stereotype. During this period of formation the new movement is performed exactly and precisely. This enables an exact performance of the whole exercise being characterized by complicated movement, economically performed. During this $3^{\text {rd }}$ phase there is an absolute harmony between the actions of the locomotors system and the activity of the internal organs. As a result there is a general increase in the functional capacity of the organism.

The following experience has been obtained by high performance athletes, their movements are precise, exact and efficient which is a result of the high rate of integration of all systems of the organism.

This period is terminated by the automatization of the abilities of movements. What has to be understood by automatization of the abilities of movements. That is a special condition during which the performance of movements takes place with little or no participation of consciousness. Only automatic movements may be performed for a longer period without fatiguing, because execution is easy and economical. The automatization of movements is lost during a longer interruption of training. This also happens, if the conditions of training are changed such as change in training facilities. During alterations inform and nature of movements, automatization may also disappear such as during change over. All these factors have to be considered not only by the physician but also by the coach and the teacher of physical education.

The development of physical qualities, like strength, speed, endurance and skill is closely related to the formation of abilities of movements, corresponding to the rules of the action of conditioned reflexes. The development of physical qualities is based on the improvement of activities of all the systems of the organism participating in a special movement. The central nervous system (CNS) plays a leading role during this process, especially its highest section the cerebral cortex.

Parallel to this, definite functional biochemical and also morphological alterations will appear in the peripheric organs. It can be stated that the trophic influence of the cerebral cortex on all the tissues and organs of the organism is increased during the process of training.

\section{CONCLUSION}

The main task of long term sport training is to develop a multi-purpose physical qualities of a sportsman that can be able further to participate in efficiency sports. Here we can differentiate the development of nervous system. The nervous activity of athletes depends on the specific sports activity performed. In discipline with accelerated reactions excitability of nervous action and lability of the nervous tissues is increased. The reduction of nervous mobility can be stated in athletes 
performing endurance disciplines. The participation of athletes in competitions is one of the most important features of sports so the development of this nervous faculty is most important for a sportsmen to adapt the different nervous tension in the prestart condition.

\section{REFERENCES}

[1] Burke, R. E. (1980) motor unit types: functional specialization in motor control in trends in Neurosciences, Vol. 3. Elsevier/North-Holland Biomedical Press, Amsterdam, pp. 255-258.

[2] Grosser, M. (1979) Determination of the fastest ten metres segment of the $100 \mathrm{~m}$ sprint in science in Athletics (eds). J. Terauds and G. D. Dales). Academic Publishers, California, pp. 71-83.

[3] Newham, D. J. Mcphail, G., Mills, K. R. and Edwards, R. H. T. (1983) ultra structural changes after concentric and ecentric contractions of human muscle. Journal of the Neurological Science. 61, 109-122.

[4] Shidlovsky, A. G. Kastrubin, E. M. and Grigoriev. Y. V. (1979) the use of central electro analgesia to Strengthen the adaptive processes in Athletes. Teoriya i Praktika Fizicheskoi Kultury, 10. 19-21.

Citation: Mir Sharif Hasan. "Adaptation of the Nervous System to Training" International Journal of Sports and Physical Education (IJSPE), vol 6, no. 3, 2020, pp. 13-15. doi: https://doi.org/10.20431/24546380.0603003 .

Copyright: () 2020 Authors. This is an open-access article distributed under the terms of the Creative Commons Attribution License, which permits unrestricted use, distribution, and reproduction in any medium, provided the original author and source are credited. 